\title{
High Accumulation of Methadone Compared with Buprenorphine in Fetal Rat Brain after Maternal Exposure
}

\author{
Mette Kongstorp, Inger Lise Bogen, Tom Stiris, and Jannike Mørch Andersen \\ Section for Drug Abuse Research, Department of Forensic Sciences (M.K., I.L.B., J.M.A.) and Department of Neonatal Intensive \\ Care (T.S.), Oslo University Hospital, and Institute of Clinical Medicine, Faculty of Medicine (M.K., T.S.), Department of Pharmacy, \\ Faculty of Mathematics and Natural Sciences (J.M.A.), and Institute of Basic Medical Sciences, Faculty of Medicine (I.L.B.), \\ University of Oslo, Oslo, Norway
}

Received May 6, 2019; accepted July 18, 2019

\begin{abstract}
Experimental animal studies are valuable in revealing a causal relationship between prenatal exposure to opioid maintenance treatment (OMT) and subsequent effects; however, previous animal studies of OMT during pregnancy have been criticized for their lack of clinical relevance because of their use of high drug doses and the absence of pharmacokinetic data. Hence, the aim of this study was to determine blood and brain concentrations in rat dams, fetuses, and offspring after continuous maternal exposure to methadone or buprenorphine during gestation and to examine the offspring for neonatal outcomes and withdrawal symptoms. Female rats were implanted with a 28 -day osmotic minipump delivering methadone (10 $\mathrm{mg} / \mathrm{kg}$ per day), buprenorphine $(1 \mathrm{mg} / \mathrm{kg}$ per day) or vehicle 5 days before mating. Continuous exposure to methadone or buprenorphine induced stable blood concentrations in the dams of $0.25 \pm 0.02 \mu \mathrm{M}$ and $5.65 \pm 0.16 \mathrm{nM}$, respectively. The fetal brain concentration of methadone $(1.89 \pm 0.35 \mathrm{nmol} / \mathrm{g})$ was twice as high as that in the maternal brain, whereas the fetal brain concentration of buprenorphine $(20.02 \pm 4.97 \mathrm{pmol} / \mathrm{g})$ was one-third the maternal brain
\end{abstract}

concentration. The opioids remained in the offspring brain several days after the exposure ceased. Offspring prenatally exposed to methadone, but not buprenorphine, displayed reduced body weight and length and increased corticosterone levels. No significant changes in ultrasonic vocalizations were revealed. Our data in rat fetuses and neonates indicate that OMT with buprenorphine may be a better choice than methadone during pregnancy.

\section{SIGNIFICANCE STATEMENT}

Concern has been raised about the use of opioid maintenance treatment during pregnancy because of the important role of the endogenous opioid system in brain development. Here, we show that the methadone concentration in the fetal rat brain was twice as high as that in the maternal brain, whereas the buprenorphine concentration was one-third the maternal concentration. Furthermore, buprenorphine allowed more favorable birth outcomes, suggesting that buprenorphine may be a better choice during pregnancy.

\section{Introduction}

The recommended therapy for opioid-dependent pregnant women is opioid maintenance treatment (OMT) with methadone or buprenorphine (WHO, 2014). OMT patients generally take better care of their health and are less likely to relapse to illicit drug use compared with those not receiving such treatment (Fischer et al., 1998; Minozzi et al., 2013); however, OMT during pregnancy may not be without risk to the unborn child. The endogenous opioid system plays a central role in neurobiological development (Sargeant et al., 2008), and opioid receptors are expressed early in embryonic life (Kim et al., 2006). In addition, because of the immaturity of the blood-brain barrier (Wolburg and Lippoldt, 2002), the fetal brain may be particularly vulnerable to exogenous opioid exposure.

Of all infants born to mothers in OMT, 40\%-90\% show signs of neonatal abstinence syndrome (Jones et al., 2010; Welle-Strand et al., 2013; Wurst et al., 2016). Prenatal exposure to methadone

https://doi.org/10.1124/jpet.119.259531. or buprenorphine has been linked to an increased risk of preterm birth (Fajemirokun-Odudeyi et al., 2006; Cleary et al., 2012; Lemon et al., 2018), lower birth weight (Sarfi et al., 2009; Cleary et al., 2012; Nørgaard et al., 2015), and smaller head circumference (Welle-Strand et al., 2013; Mactier et al., 2014; Bier et al., 2015). Increasing evidence also indicates a relationship between prenatal OMT exposure and long-lasting negative effects on different outcomes, such as impaired cognitive functioning and attention and behavioral, psychomotor, and visual problems (de Cubas and Field, 1993; Sundelin Wahlsten and Sarman, 2013; Nygaard et al., 2015, 2017; Monnelly et al., 2019). Because OMT is associated with multiple confounding factors, (e.g., polysubstance use and genetic and socioeconomic differences) (Konijnenberg and Melinder, 2011), it is difficult to draw conclusions about prenatal opioid exposure and its subsequent effects. To confirm a causal relationship, controlled experimental studies with methadone and buprenorphine are needed, but ethical concerns do not allow such studies to be performed in pregnant women.

ABBREVIATIONS: ANOVA, analysis of variance; ce, collision energy; cv, cone voltage; GD, gestation day; OMT, opioid maintenance treatment; PND, postnatal day; USV, ultrasonic vocalizations. 
Previous animal studies of OMT during pregnancy have been criticized for their lack of clinical relevance due to of their use of high drug doses (Farid et al., 2008; Ross et al., 2015). Since pharmacokinetic data for methadone and buprenorphine in rodents are missing, we do not know if the doses usually administrated result in blood concentrations comparable to those reported in humans (Gordon et al., 2010; Concheiro et al., 2011; Bartu et al., 2012). Moreover, there is a lack of knowledge concerning the distribution of methadone and buprenorphine to the fetus. The aim of this study was therefore to investigate the blood and brain opioid concentrations in rat fetuses and offspring continually exposed to methadone or buprenorphine through exposure of the pregnant dams. The fetal opioid concentrations were compared with the blood and brain opioid concentrations in the dams. Moreover, the pups were examined for neonatal outcomes and symptoms of withdrawal the first 2 weeks after birth.

\section{Materials and Methods}

Animals. The present study was approved by the Norwegian Animal Research Authority (Norwegian Food Safety Authority, Oslo, Norway) and performed in accordance with the laws and regulations controlling experiments and procedures on research animals in Norway. Female (350.4 $\pm 5.9 \mathrm{~g}, n=75)$ and male (12 weeks, $n=38$ ) Sprague-Dawley rats were obtained from Taconic Biosciences (Ejby, Denmark). Upon arrival, all animals were allowed 1 week of habituation. The rats were housed two to three per cage with free access to food and water under an artificial 12-hour light/dark cycle, $50 \% \pm 10 \%$ humidity, and $21 \pm 2{ }^{\circ} \mathrm{C}$. The study was performed in two separate experiments. In the first experiment, the blood and brain opioid concentrations in dams and fetuses were examined during gestation. In the second experiment, disturbance of the dams was reduced to a minimum to avoid the possible influence of maternal stress, and offspring effects were examined. A total of 320 offspring were included in the study.

Drugs. Methadone-HCl (MW 345.91; Sigma, Oslo, Norway) and buprenorphine-HCl (MW 504.11; Chiron AS, Trondheim, Norway) were dissolved in sterile water (Fresenius Kabi, Hadeland, Norway). Sterile water was used as vehicle owing to the low solubility of buprenorphine in saline.

Therapeutic doses of methadone and buprenorphine have been reported to be $20-260$ and $0.8-32 \mathrm{mg} /$ day, respectively, in pregnant women (Gordon et al., 2010; Concheiro et al., 2011; Bartu et al., 2012; Welle-Strand et al., 2013), corresponding to $0.3-3.7 \mathrm{mg} / \mathrm{kg}$ per day methadone and $0.01-0.45 \mathrm{mg} / \mathrm{kg}$ per day buprenorphine. In humans, methadone and buprenorphine have half-lives of 20-30 hours (Saxon et al., 2013); however, methadone and buprenorphine are eliminated much faster in rodents $\left(t_{1 / 2}=2-2.5\right.$ hours) (Ohtani et al., 1994; Andersen et al., 2011). To compensate for the rapid metabolism, the female rats were exposed to $10 \mathrm{mg} / \mathrm{kg}$ per day methadone or $1 \mathrm{mg} / \mathrm{kg}$ per day buprenorphine throughout gestation. The drug doses are the same as previously used (Hutchings et al., 1992; Robinson and Wallace, 2001; Hung et al., 2013; Chen et al., 2015) and are based on the salt form.

Pump Implantation. An osmotic minipump was used to maintain stable and continuous exposure of the dams to opioids. Five days before mating (one female to one drug-naïve male), the female rat was implanted with a 28-day osmotic minipump with a $2.5-\mu \mathrm{l} / \mathrm{h}$ delivery rate (2ML4; Alzet, Cupertino, CA) under isoflurane anesthesia (Baxter International, Deerfield, IL). The pumps were filled with methadone$\mathrm{HCl}$ (initial dose $10 \mathrm{mg} / \mathrm{kg}$ per day, $n=26$ ), buprenorphine-HCl (initial dose $1 \mathrm{mg} / \mathrm{kg}$ per day, $n=33$ ), or vehicle (sterile water, $n=16$ ) under sterile conditions. For an overview of the experimental setup, see Fig. 1. A small lateral incision was made in the dorsal area behind the neck, the pump was inserted subcutaneously (s.c.) with the opening facing the anterior direction, and the incision site was closed with nonabsorbable
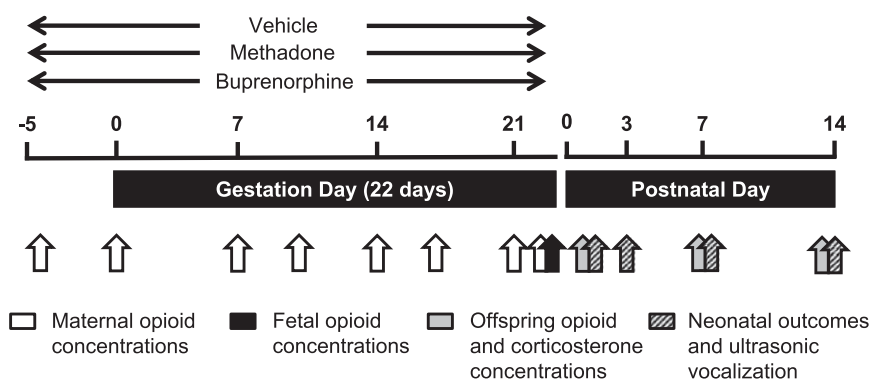

Fig. 1. Schematic overview of the study. Female rats were implanted with a 28-day osmotic minipump delivering vehicle (sterile water), methadone (10 mg/kg per day), or buprenorphine $(1 \mathrm{mg} / \mathrm{kg}$ per day) 5 days before mating (GD -5). The maternal blood concentration of the administered opioid was measured the day after implantation (GD -4), on the day of mating (GD 0), and on GD 7, 10, 14, 17, and 21. On GD 22, the blood and brain concentrations of the administered opioid were measured in the dams and fetuses. The offspring were examined for neonatal outcomes on PND 1, for opioid and corticosterone concentrations on PND 17 and 14 , and for ultrasonic vocalizations on PND 1, 3, 7, and 14.

stiches. The animals were allowed to recover on heating pads under observation before they were placed in individual cages. Metacam $(0.3 \mathrm{mg} / \mathrm{kg}$, s.c. $)$ was given as an analgesic during and 5 to 6 hours after the surgery.

Blood and Brain Sampling from Dams and Fetuses. Blood samples were collected from the dams 1 day after implantation of the pump [gestation day (GD) -4], on the day of mating (GD 0), and on GD $7,10,14,17$, and 21 (Fig. 1). After 5-10 minutes on a heating pad, the animal was restrained, the hind leg was shaved, Vaseline was applied, and the lateral saphenous vein was punctured with a cannula $(25 \mathrm{G})$. Approximately $250 \mu \mathrm{l}$ of blood was collected in a tube containing $30 \mu \mathrm{l}$ of heparin (100 IU/ml; LEO Pharma AS, Lysaker, Norway) to inhibit clotting. In duplicate, $100 \mu \mathrm{l}$ of each blood sample was transferred to a 5-ml tube and immediately frozen in liquid $\mathrm{N}_{2}$.

On GD 22, blood and brain tissue were collected from dams and fetuses. The dams were anesthetized by isoflurane, and blood was collected by cardiac puncture with a syringe ( $21 \mathrm{G}$ cannula) prefilled with $80 \mu \mathrm{l}$ of heparin. In duplicate, $100 \mu \mathrm{l}$ of each blood sample was transferred to a 5-ml tube and immediately frozen in liquid $\mathrm{N}_{2}$. An abdominal incision was made, the embryonic sacs containing the fetuses were opened, and the fetuses were immediately decapitated. Trunk blood was collected from each fetus and pooled (two to five offspring) to obtain a volume of $100 \mu \mathrm{l}$ in a tube containing $10 \mu \mathrm{l}$ of heparin.Brains were collected from four fetuses from each litter and immediately frozen in liquid $\mathrm{N}_{2}$. After the embryonic sacs were removed, the dam was decapitated, and the cerebrum was removed, rinsed with $0.9 \% \mathrm{NaCl}$, and quickly frozen in liquid $\mathrm{N}_{2}$. After blood and brain harvesting, the osmotic pump was released, and the remaining solution was extracted and analyzed for opioid concentration.

Blood and Brain Sampling from Offspring. The day of birth was defined as postnatal day (PND) 0 . On PND 1, 7, and 14, one or two offspring from each litter were randomly chosen for blood and brain harvesting. The pups were anesthetized by isoflurane, and a blood sample was collected by cardiac puncture using a syringe ( $25 \mathrm{G}$ cannula) prefilled with $80 \mu \mathrm{l}$ of heparin. In duplicate, $100 \mu \mathrm{l}$ of each blood sample was transferred to a 5 -ml plastic tube and immediately frozen in liquid $\mathrm{N}_{2}$. After blood sampling, the pups were decapitated, and the brains were harvested, weighed, and frozen immediately in liquid $\mathrm{N}_{2}$. All blood samples and brain tissue were stored at $-80^{\circ} \mathrm{C}$ for further analysis.

Determination of Methadone, Buprenorphine, and Corticosterone Concentrations in Blood and Brain Tissue. The cerebrum was homogenized in ice-cold $0.32 \mathrm{M}$ sucrose ( $100 \mathrm{mg}$ of brain $/ \mathrm{ml}$ ) containing cOmplete protease inhibitor cocktail (Roche, Basel, Switzerland), batched and stored at $-80^{\circ} \mathrm{C}$ for analysis.

The concentrations of methadone and buprenorphine in the blood and brain tissue and the blood concentration of corticosterone were 
measured using an ultraperformance liquid chromatography-tandem mass spectrometry method established in our laboratory. Working solutions for five calibrators and four quality controls were prepared separately in $5 \mathrm{mM}$ ammonium formate buffer ( $\mathrm{pH}$ 3.1). The calibrators (1-2000 nM for methadone, 0.1-200 nM for buprenorphine, and $0.35-1430 \mathrm{nM}$ for corticosterone) and quality controls (1.2-1200 nM for methadone, $0.12-120 \mathrm{nM}$ for buprenorphine and $0.4-800 \mathrm{nM}$ for corticosterone) were prepared by diluting $50 \mu \mathrm{l}$ of the working solutions with $100 \mu \mathrm{l}$ blood from unexposed rats. Fifty microliters of an internal standard (methadone- $\mathrm{d}_{9}$, buprenorphine- $\mathrm{d}_{6}$, and corticosterone- $\mathrm{d}_{4}$ ) and $100 \mu \mathrm{l}$ ammonium bicarbonate $(0.2 \mathrm{M}, \mathrm{pH}$ 9.3) were added to each sample before vortexing. Next, $1.2 \mathrm{ml}$ of ethyl acetate:heptane (1:4) was added, and the samples were mixed and centrifuged at $4^{\circ} \mathrm{C}$ at $4750 \mathrm{rpm}$ $(3600 \mathrm{~g})$ for 4 minutes. The organic phase was then transferred to a $5-\mathrm{ml}$ glass tube, evaporated to dryness under a stream of $\mathrm{N}_{2}$ at $50^{\circ} \mathrm{C}$, reconstituted with $100 \mu \mathrm{l}$ 90:10 ammonium formate buffer $(10 \mathrm{mM}$, $\mathrm{pH}$ 3.1): $\mathrm{MeOH}$, and transferred to auto sampler vials.

The samples were analyzed using an Acquity UPLC system coupled to an Xevo-TQS triple quadrupole mass spectrometer with an electrospray ionization interface (Waters Corporation, Milford, MA). Methadone, buprenorphine, and corticosterone were separated on a $\mathrm{BEH}$ $\mathrm{C}_{18}$ column $(2.1 \times 50 \mathrm{~mm}, 1.7 \mu \mathrm{m}$; Waters $)$ using gradient elution with a mobile phase consisting of $5 \mathrm{mM}$ ammonium formate buffer, $\mathrm{pH} 10.2$ (solvent A), and $\mathrm{MeOH}$ (solvent B), a flow rate of $0.4 \mathrm{ml} / \mathrm{min}$ and a column temperature of $60^{\circ} \mathrm{C}$. The gradient had a total run time of 5 minutes with the following profile: $0-0.1$ minutes; $5 \% \mathrm{~B}$, 0.1-0.18 minutes; $5 \%-30 \% \mathrm{~B}, 0.18-1.6$ minutes; $30 \%-50 \% \mathrm{~B}$, 1.6-2.3 minutes; $50 \%-90 \%$ B, 2.3-2.7 minutes; $90 \%$ B, $2.7-2.76$ minutes; $90 \%-98 \%$ B, 2.76-3.5 minutes; $98 \%$ B, 3.5-3.6 minutes; $98 \%-5 \%$ B, 3.6-5 minutes; $5 \%$ B. The injection volume was $5 \mu \mathrm{l}$. MS/MS analysis was performed with positive ionization using multiple reaction monitoring mode. A capillary voltage of $3 \mathrm{kV}$, source temperature of $150^{\circ} \mathrm{C}$, desolvation gas temperature of $500^{\circ} \mathrm{C}$, cone gas flow of 300 liters per hour, and desolvation gas flow of 1000 liters per hour were used. The multiple reaction monitoring transitions for the compounds had the following values: methadone: $\mathrm{m} / z$ $310.22>223.10$ [cone voltage (cv) $30 \mathrm{~V}$, collision energy (ce) $25 \mathrm{eV}$ ] and $\mathrm{m} / z 310.22>265.16$ (cv $30 \mathrm{~V}$, ce $18 \mathrm{eV}$ ); buprenorphine: $\mathrm{m} / z 468.31>$ $396.22(\mathrm{cv} 60 \mathrm{~V}$, ce $40 \mathrm{eV}$ ) and $m / z 468.31>414.26(\mathrm{cv} 60 \mathrm{~V}$, ce $40 \mathrm{eV})$; and corticosterone: $\mathrm{m} / z 347.20>121.10$ (cv $25 \mathrm{~V}$, ce $25 \mathrm{eV}$ ) and $\mathrm{m} / z$ $347.20>329.10$ (cv $25 \mathrm{~V}$, ce $15 \mathrm{eV}$ ). Acquisition and processing were performed using Masslynx software (version 4.1; Waters). The limits of quantification were $1 \mathrm{nM}$ for methadone, $0.1 \mathrm{nM}$ for buprenorphine, and $0.7 \mathrm{nM}$ for corticosterone. The retention times for methadone, buprenorphine, and corticosterone were $2.9,3.2$, and 2.4 minutes, respectively. The correlation coefficient was $>0.99$, and the deviation of the quality controls was $< \pm 20 \%$.

Neonatal Outcomes. On PND 1, all litters were examined for the number of offspring and the number of stillborn, and all pups were examined for sex, body weight, and body length.

Ultrasonic Vocalization. Ultrasonic vocalizations (USVs) were examined in two randomly selected pups from each litter on PND 1, 3, 7, and 14. Each pup was isolated from its dam and littermates and injected (i.p.) with naltrexone $(1 \mathrm{mg} / \mathrm{kg}$ ) or an equal volume of $0.9 \% \mathrm{NaCl}$ 15 minutes before recording. USVs were recorded for 6 minutes using the UltraVox 3.0 Ultrasound Microphone (Noldus Information Technology, Wageningen, The Netherlands). During recording, the pup was placed in a plastic cage with regulated heating, and the microphone was placed approximately $15 \mathrm{~cm}$ above the animal. After recording, the pup was returned to its home cage. The recordings were analyzed by a researcher blinded to the treatment of the pups and by using UltraVox TX 3.0 software (Noldus Information Technology). All calls with a frequency of $20-60 \mathrm{kHz}$ were counted (Hofer et al., 2002).

Data and Statistical Analysis. All data are presented as the mean \pm S.E.M. unless stated otherwise. For analysis of treatment over time, repeated measures analysis of variance (ANOVA) was used, followed by Tukey's post hoc test (Fig. 2). For comparisons of two groups, a two-tailed Student's $t$ test was used (Fig. 3). One-way ANOVA followed by Tukey's post hoc test was used to compare the three treatment groups (Fig. 4; Table 1 ). $P$ values $<0.05$ were considered statistically significant. The statistical analyses were conducted by SPSS Statistics (version 25; IBM, Chicago, IL).

\section{Results}

A total of 75 female rats were implanted with an osmotic minipump. Seven animals were euthanized during pregnancy for health problems or complications with the pump. Six vehicle-exposed, 5methadone-exposed, and 13 buprenorphineexposed females did not mate successfully.

Maternal Blood Concentrations of Methadone and Buprenorphine. The maternal blood concentrations were stable at $0.25 \pm 0.02 \mu \mathrm{M}$ for methadone and $5.65 \pm 0.16 \mathrm{nM}$ for buprenorphine throughout gestation (GD 7-21; Fig. 2, A and B). No significant differences were observed in body weights between the vehicle-, methadone- or buprenorphine-exposed dams (Fig. 2C). By GD 21, the mean weight gain was $72.0 \pm$ $6.5 \mathrm{~g}$. Due to the weight gain, the initial doses of $10 \mathrm{mg} / \mathrm{kg}$ per day methadone and $1 \mathrm{mg} / \mathrm{kg}$ per day buprenorphine were reduced to approximately 8 and $0.8 \mathrm{mg} / \mathrm{kg}$ per day, respectively. On GD 22, the drug concentration of the solutions remaining in the pump was $99 \% \pm 4 \%$ of the initial concentration (data not shown).

Blood and Brain Concentrations of Methadone in Dams, Fetuses, and Offspring. After continuous exposure to methadone throughout gestation, the blood methadone concentration in the dams on GD 22 was $0.30 \pm 0.04 \mu \mathrm{M}$, whereas the brain concentration was 2.8 times higher $(0.84 \pm$ $0.10 \mathrm{nmol} / \mathrm{g} ; P<0.001$; Fig. 3A). The fetal blood concentration on GD 22 was $0.48 \pm 0.08 \mu \mathrm{M}$, whereas the fetal brain concentration was $1.89 \pm 0.35 \mathrm{nmol} / \mathrm{g}$, four times higher than that in the blood ( $P<0.01$; Fig. 3A). Moreover, the methadone concentration in the fetal blood was 1.6 times higher than that in the maternal blood $(P<0.01)$, and the fetal brain concentration was 2.3 times higher than the maternal brain concentration $(P<0.01)$. On PND 1 , the offspring blood and brain concentrations were $0.02 \pm 0.01 \mu \mathrm{M}$ and $0.13 \pm 0.05 \mathrm{nmol} / \mathrm{g}$, respectively (Fig. 3C). On PND 7, no methadone was detected in the offspring blood, whereas the offspring brain concentration was $0.01 \pm 0.01 \mathrm{nmol} / \mathrm{g}$, which was significantly lower than on PND 1 ( $P<0.01$; Fig. 3C).

Blood and Brain Concentrations of Buprenorphine in Dams, Fetuses, and Offspring. After continuous exposure to buprenorphine throughout gestation, the blood buprenorphine concentration in the dams on GD 22 was $5.69 \pm 1.44 \mathrm{nM}$, whereas the concentration in the brain was 10 times higher $(60.22 \pm 8.21 \mathrm{pmol} / \mathrm{g} ; P<0.001$; Fig. 3B). The fetal blood concentration on GD 22 was $4.56 \pm 0.93 \mathrm{nM}$, whereas the brain concentration was $20.02 \pm 4.97 \mathrm{pmol} / \mathrm{g}$, four times higher than that in the fetal blood ( $P<0.05$; Fig. 3B). Although the fetal and maternal blood concentrations were within the same range, the fetal brain concentration was one-third the maternal brain concentration $(P<0.001$; Fig. 3B). On PND 1, the offspring blood and brain concentrations were $0.36 \pm 0.11 \mathrm{nM}$ and $4.98 \pm 1.01 \mathrm{pmol} / \mathrm{g}$, respectively (Fig. 3D). On PND 7, no buprenorphine was detected in the offspring blood, whereas the brain concentration was $0.80 \pm 0.27 \mathrm{pmol} / \mathrm{g}$, which was significantly lower than on PND 1 ( $P<0.01$; Fig. 3D). 
A

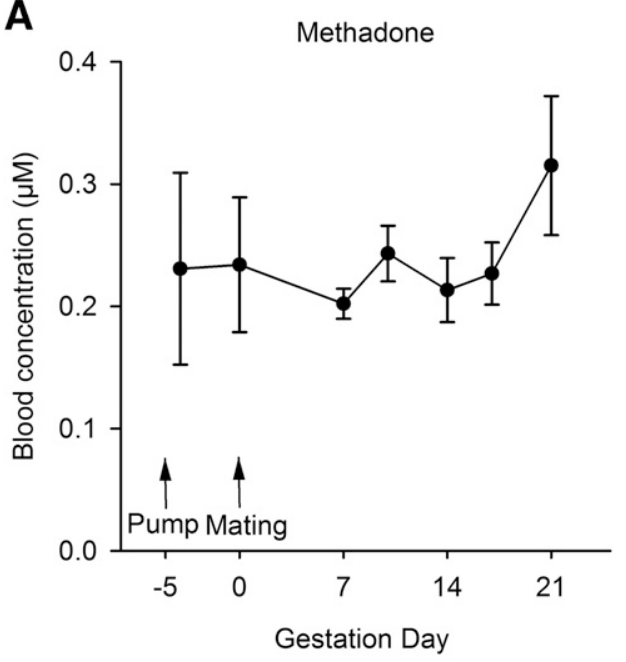

C

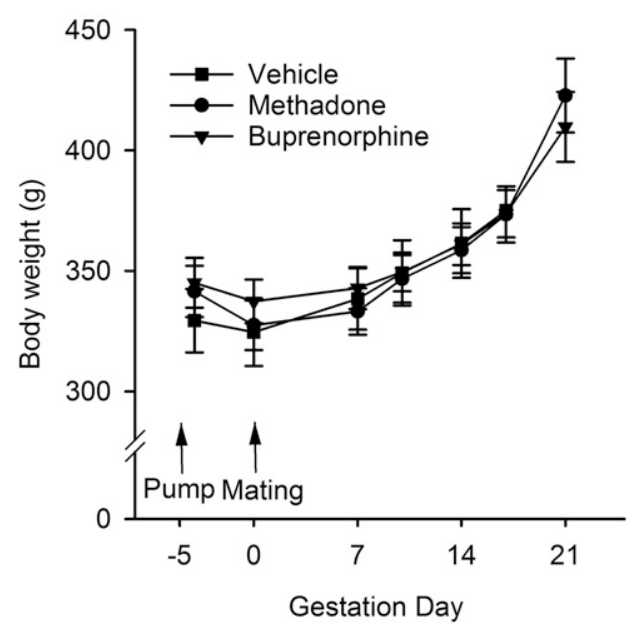

B

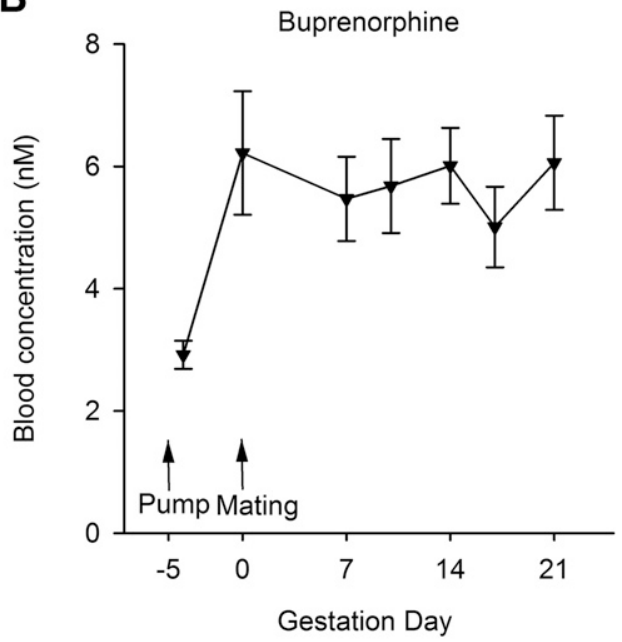

Fig. 2. The blood concentrations of (A) methadone $(\mu \mathrm{M})$ and $(\mathrm{B})$ buprenorphine $(\mathrm{nM})$ in the female rats implanted with an osmotic minipump delivering methadone (10 $\mathrm{mg} / \mathrm{kg}$ per day) or buprenorphine ( $1 \mathrm{mg} / \mathrm{kg}$ per day), respectively, 5 days before mating (GD -5). Blood concentrations were measured the day after implantation (GD -4), on the day of mating (GD 0), and on GD 7, 10, 14, 17, and 21, $n=7$. (C) The body weights of the dams exposed to vehicle, methadone, or buprenorphine before and during gestation, $n=5-12$. Data are presented as the mean \pm S.E.M.; no significant differences were revealed, repeated measures ANOVA.
Neonatal Outcomes after Prenatal Exposure to Methadone or Buprenorphine. Maternal exposure to methadone or buprenorphine did not affect litter size, the number of stillborn pups, or the sex ratio (Table 1). Compared with the vehicle- and buprenorphine-exposed offspring, the pups prenatally exposed to methadone showed significantly reduced body weight $(P<0.01)$ and length $(P<0.001)$ on PND 1 ; however, when the litters $(n=10)$ instead of the individual pups ( $n=99-119$ ) were compared, no significant differences were observed in body weight or length. No differences were observed in the offspring brain weight (Table 1).

Blood Corticosterone Concentrations and USVs in Offspring Prenatally Exposed to Methadone or Buprenorphine. On PND 1, pups prenatally exposed to methadone exhibited significantly higher blood levels of the stress hormone corticosterone compared to both the vehicle- and buprenorphine-exposed offspring ( $P<0.05$; Fig. 4A). No differences were observed on PND 7 or 14 . The USV recordings did not reveal any significant differences between the three groups on PND 1, 3, 7, or 14 (Fig. 4B, left panel). Moreover, compared with saline pretreatment, pretreatment with naltrexone $(1 \mathrm{mg} / \mathrm{kg}) 15$ minutes before recording did not affect the vocalization (data not shown), which is consistent with the low opioid concentrations detected in the offspring
(Fig. 3, C and D). However, the number of calls varied considerably between the individual pups from all groups (Fig. 4B, right panel). On PND 7, approximately $50 \%$ of the opioidexposed offspring displayed more calls than the pup exhibiting most calls in the vehicle group. Similar findings were observed on PND 3 for the methadone-exposed offspring (Fig. 4B, right panel).

\section{Discussion}

In the present study, we have shown that continuous exposure to methadone or buprenorphine, at doses of 10 and $1 \mathrm{mg} / \mathrm{kg}$ per day, respectively, provided stable blood concentrations in pregnant rats that were comparable to those reported in pregnant women in OMT. The concentration of methadone in the fetal brain was twice that in the maternal brain, whereas the fetal brain concentration of buprenorphine was one-third the maternal brain concentration. Moreover, offspring prenatally exposed to methadone, but not buprenorphine, displayed reduced body weight and length and an increased blood corticosterone level the day after birth.

Previous animal studies of prenatal exposure to methadone or buprenorphine have been criticized for their lack of clinical 
A
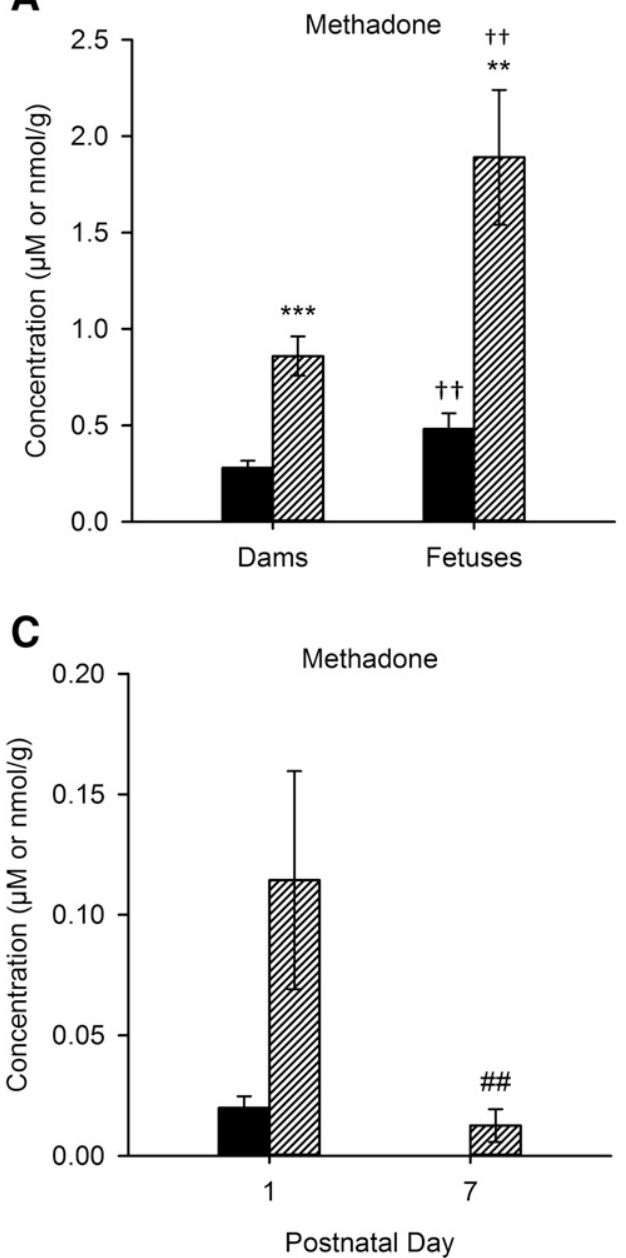

B
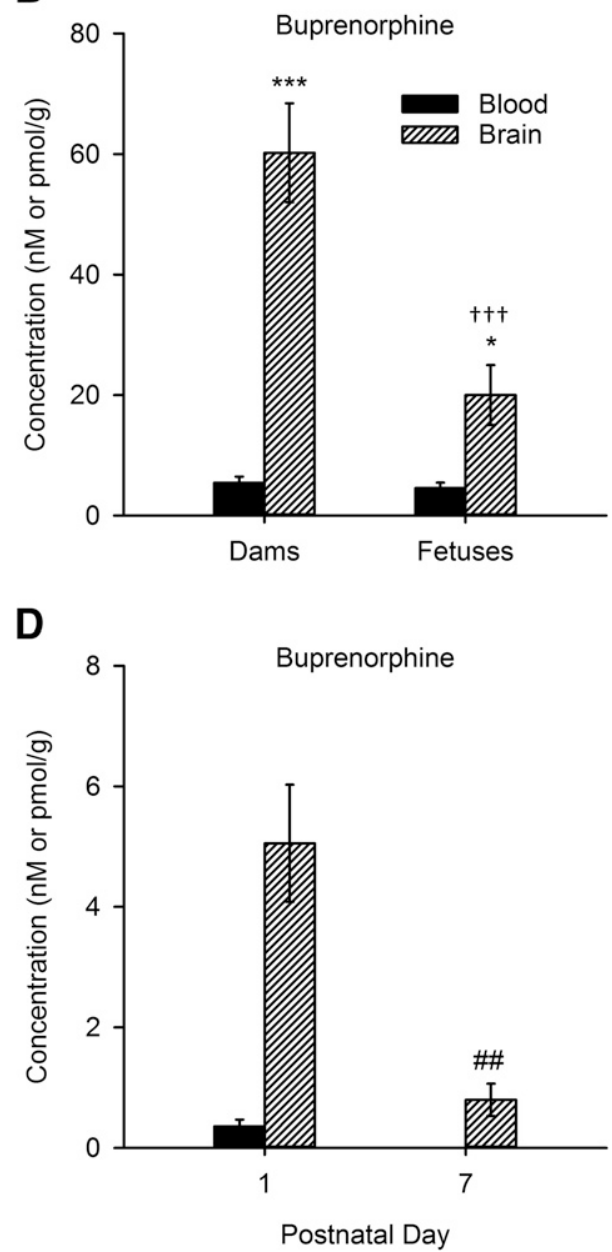

Fig. 3. The blood and brain concentrations of (A) methadone (blood, $\mu \mathrm{M}$; brain, $\mathrm{nmol} / \mathrm{g}$ ) and (B) buprenorphine (blood, nM; brain, $\mathrm{pmol} / \mathrm{g}$ ) in the dams and fetuses on GD 22. Female rats were implanted with a 28 -day osmotic minipump delivering methadone $(10 \mathrm{mg} / \mathrm{kg}$ per day) or buprenorphine $(1 \mathrm{mg} / \mathrm{kg}$ per day) 5 days before mating $($ GD -5$)$. The blood and brain concentrations of (C) methadone and (D) buprenorphine in the offspring on PND 1 and 7 . The maternal blood and brain, $n=7$; the fetal blood, $n=5-7$ (pooled from two to five fetuses); the fetal brain, $n=25$ or 26 (from seven litters); and the offspring blood and brain, $n=10-16$ (from seven to eight litters). The data are presented as the mean \pm S.E.M. $* P<0.05 ; * * / \dagger P<0.01$ $* * * 1+\uparrow P<0.001$; *compared with blood; 'compared with the respective maternal concentration, two-tailed paired student's $t$ test; ${ }^{\# \#} P<0.01$ compared with PND1, two-tailed unpaired student's $t$ test. relevance owing to the use of high drug doses and the absence of pharmacokinetic data (Farid et al., 2008; Ross et al., 2015). To our knowledge, only one previous study has reported methadone concentrations in pregnant rats after repeated daily administrations (Hutchings et al., 1976); however, blood sampling was performed at one single undefined time point. The present data are therefore the first to demonstrate that continuous exposure to high doses of methadone $(10 \mathrm{mg} / \mathrm{kg}$ per day) or buprenorphine (1 $\mathrm{mg} / \mathrm{kg}$ per day), used previously (Hutchings et al., 1992; Robinson and Wallace, 2001), induces stable blood concentrations of $0.25 \pm 0.02 \mu \mathrm{M}$ and $5.65 \pm 0.16 \mathrm{nM}$, respectively, throughout gestation. These concentrations are in the same range as plasma concentrations of pregnant women in OMT, which have been reported to be $0.08-1.7 \mu \mathrm{M}$ for methadone and $0.3-16.0 \mathrm{nM}$ for buprenorphine (Doberczak et al., 1993; Johnson et al., 2001; Drozdick et al., 2002; Jansson et al., 2007; Concheiro et al., 2010, 2011; Gordon et al., 2010; Bartu et al., 2012). In agreement with previous studies that have reported accumulation of methadone and buprenorphine in the rat brain after acute exposure (Gabrielsson et al., 1985; Pontani et al., 1985), we also found higher opioid concentrations in the brain than in the blood of pregnant rats.

A major concern of OMT during pregnancy is that methadone and buprenorphine cross the placenta and are distributed in the fetal tissue (Sarman, 2000; Nanovskaya et al., 2002). We found the methadone concentration to be 1.6 times higher in fetal blood than in maternal blood, whereas the fetal blood concentration of buprenorphine was within the same range as the blood concentration in the dams. Similar ratios have been reported after a single injection of methadone in rats (Gabrielsson et al., 1985) and buprenorphine in mice (Coles et al., 2009). This somewhat lower transfer of buprenorphine than of methadone is also consistent with in vitro studies of the human placenta (Nekhayeva et al., 2005; Gordon et al., 2010).

The four times higher concentration of methadone and buprenorphine in the fetal brain than in the blood demonstrates that, as methadone or buprenorphine enters the fetal circulation, both drugs accumulate in neuronal tissue. This is concerning because the endogenous opioid system plays a key role in neurobiological development (Sargeant et al., 2008). Previous animal studies have shown that exposure to opioids during fetal or early life affects the migration and survival of neurons, leading to an overall inhibition of brain growth and development (Zagon and McLaughlin, 1977; Wu et al., 2001; Bajic et al., 2013), which may cause acute effects (Hutchings et al., 1979; Hein et al., 1988; Kunko et al., 1996) and longlasting neurobiological changes. Indeed, exposure to methadone or buprenorphine during development has caused impaired learning and memory (Zagon et al., 1979; Van Wagoner et al., 1980; Chen et al., 2015), anxiety and depression (Daly et al., 2012; Hung et al., 2013; Chen et al., 2015), and altered pain thresholds in adolescent and adult 
A

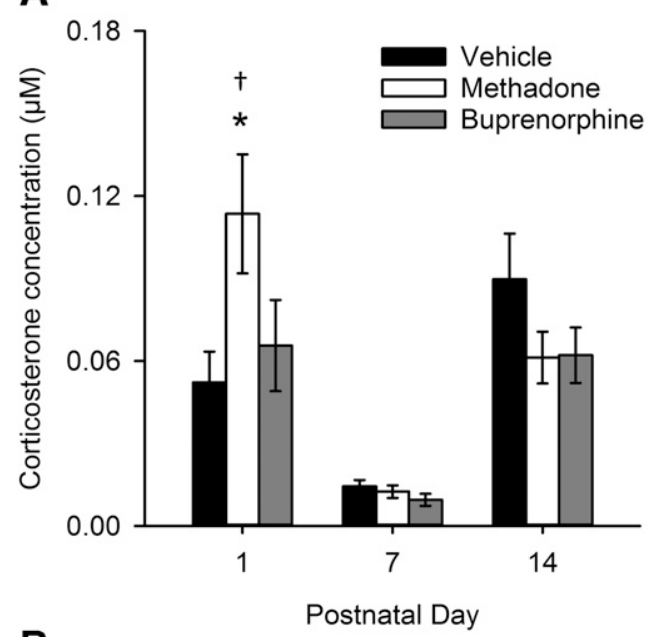

B
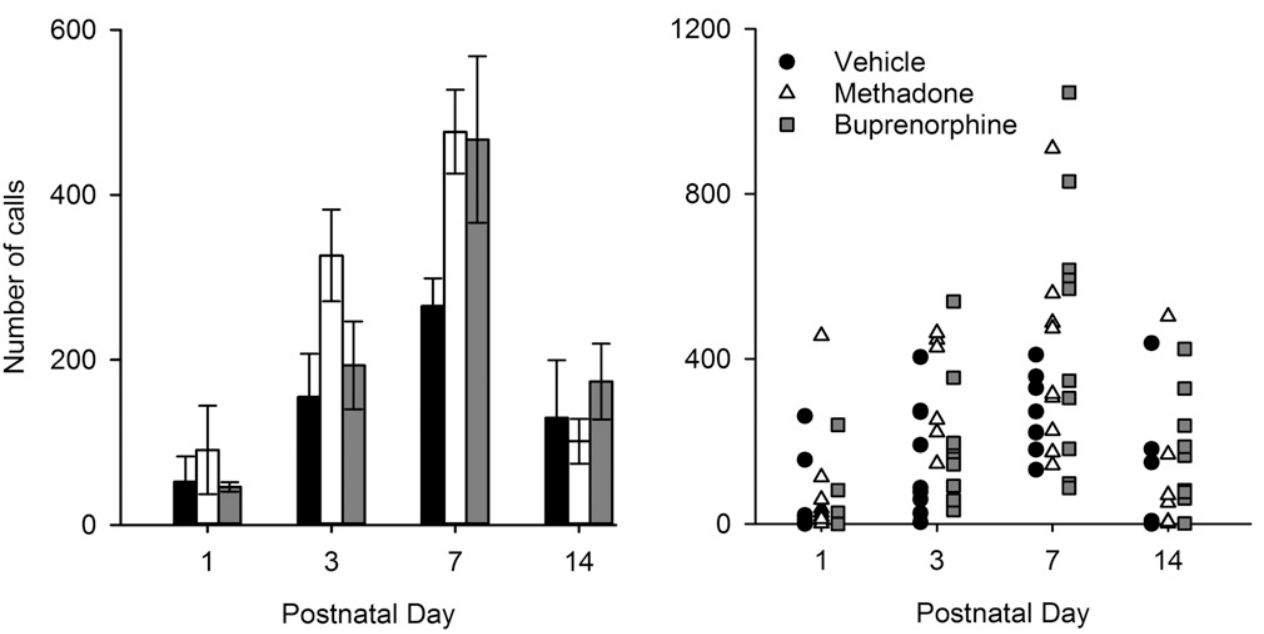

Fig. 4. Stress hormone levels and vocalizations in the offspring prenatally exposed to vehicle, methadone $(10 \mathrm{mg} / \mathrm{kg}$ per day) or buprenorphine (1 mg/kg per day). (A) The blood concentration $(\mu \mathrm{M})$ of corticosterone in the offspring on PND 1, 7, and 14, $n=$ 9-16 (from seven to nine litters). (B) USVs, measured as the number of calls, on PND 1, 3,7 , and $14, n=6-10$. Left panel displays the mean number of calls; right panel shows variations in the number of calls in each treatment group. The data are presented as the mean \pm S.E.M. or as single data points; $* P<0.05$ compared with vehicle; ${ }^{\top} P<0.05$ compared with buprenorphine, one-way ANOVA followed by Tukey's post hoc test.

rats (Zagon and McLaughlin, 1982; Chiang et al., 2015). There are also indications of negative long-lasting behavioral effects in children born to mothers in OMT (Konijnenberg and Melinder, 2011; Monnelly et al., 2019).

The methadone concentration in the fetal brain was twice as high as that in the maternal brain. Similar findings have been reported previously after a single injection (Peters et al., 1972). This is alarming as it suggests that methadone treatment

TABLE 1

Litter size, number of stillborns, sex ratio, and pup body weight, body length, and brain weight on PND 1

\begin{tabular}{|c|c|c|c|}
\hline & Vehicle & Methadone & Buprenorphine \\
\hline Litter size $\mathrm{e}^{a}$ & $11.9 \pm 0.8$ & $11.1 \pm 1.1$ & $9.9 \pm 0.8$ \\
\hline $\begin{array}{l}\text { Stillborn (no. of } \\
\text { dead/total) }\end{array}$ & $2 / 119$ & $5 / 111$ & $2 / 99$ \\
\hline $\begin{array}{l}\text { Sex ratio (male/ } \\
\quad \text { female) })^{a}\end{array}$ & 1.1 & 1.2 & 1.4 \\
\hline Body weight $(\mathrm{g})^{b}$ & $7.08 \pm 0.13$ & $6.59 \pm 0.13^{* *, \dagger \dagger}$ & $7.17 \pm 0.08$ \\
\hline Body length $(\mathrm{cm})^{b}$ & $5.24 \pm 0.05$ & $4.92 \pm 0.05^{* * *, \dagger \dagger \dagger}$ & $5.31 \pm 0.05$ \\
\hline Brain weight $(\mathrm{g})^{c}$ & $0.26 \pm 0.01$ & $0.25 \pm 0.01$ & $0.25 \pm 0.01$ \\
\hline
\end{tabular}

${ }_{b}^{a} n=10$ litters.

${ }^{b} n=99-119$ (from 10 litters).

${ }^{c_{n}}=11-16$ (from 10 litters)

${ }^{* *} \Gamma^{\dagger \dagger} P<0.01$; ***ंग $P<0.001$ * *ompared with vehicle, ${ }^{\dagger}$ compared with buprenorphine, one-way ANOVA, Tukey's post hoc test. Not significant when comparing mean litter weight or length. during pregnancy leads to a larger burden for the fetal brain than for the maternal brain. In contrast to methadone, the buprenorphine concentration in the fetal brain was one-third the maternal brain concentration. Moreover, even though the buprenorphine dose used in the current study was one-tenth the methadone dose, the fetal brain concentration of buprenorphine was 95 times lower than that of methadone. It is important to note that methadone and buprenorphine are different with respect to being full versus partial agonists, their affinity and dissociation rate for the $\mu$-opioid receptor, and their action on the NMDA receptor (Volpe et al., 2011; Drewes et al., 2013). Thus, the effect of a drug on the developing brain is not only dependent on the drug concentration but also on its pharmacological properties.

The concentrations of methadone and buprenorphine in the 1-day-old pups were lower than the concentrations in the fetuses, but as in fetuses, the brain opioid concentrations were considerably higher than the concentrations in blood. Moreover, methadone and buprenorphine were still present in the offspring brains on PND 7. We cannot completely exclude a minor drug exposure through lactation the first days after birth; however, since the pumps were empty around the time of delivery, our findings indicate slow drug elimination from the neonatal brain. 
The pups prenatally exposed to methadone were born with significantly lower body weight and body length compared with those of the vehicle- and buprenorphine-exposed offspring; however, no significant differences were observed in these measures when comparing the litters instead of the individual pups. In previous animal studies both reduced birth weights (Hutchings et al., 1979; Robinson et al., 1991; Kunko et al., 1996; Robinson and Wallace, 2001), and no differences have been reported after prenatal methadone exposure (Chiang et al., $2010,2015)$. In agreement with our results, rat pups prenatally exposed to buprenorphine seem to have more favorable birth outcomes compared with those of methadone-exposed pups (Hutchings et al., 1996; Chiang et al., 2010). Additionally, human studies have reported a reduced incidence of preterm birth, higher birth weights and larger head circumferences after maternal treatment with buprenorphine thanmethadone (Welle-Strand et al., 2013; Zedler et al., 2016).

Offspring prenatally exposed to methadone exhibited increased blood levels of the stress hormone corticosterone compared with those in both the vehicle- and buprenorphineexposed offspring. This finding may be explained by the more rapid elimination of methadone and may therefore be a sign of opioid withdrawal (Hamilton et al., 2013); but it may also be due to the methadone exposure itself (Bartolome and Kuhn, 1983). USVs, which are used as a measure of withdrawal in rodents (Barr et al., 1998), were not significantly different between the groups; however, the number of calls varied considerably between individual pups, especially in the opioid-treated groups, where approximately $50 \%$ of the methadone- and buprenorphine-exposed offspring exhibited increased vocalizations on PND 7. Large variations in abstinences have also been reported in newborns (Jones et al., 2010; Welle-Strand et al., 2013; Wurst et al., 2016). In line with our observations, maternal treatment with methadone is associated with a more severe neonatal abstinence syndrome compared with buprenorphine, shown by longer hospital stay and an increased need for treatment (Jones et al., 2010; Meyer et al., 2015).

In conclusion, our pharmacokinetic data show that the exposure regimen used in the present study and in previous animal studies of OMT, with continuous exposure to high doses of methadone $(10 \mathrm{mg} / \mathrm{kg}$ per day) or buprenorphine $(1 \mathrm{mg} / \mathrm{kg}$ per day), results in blood concentrations in pregnant rats comparable to those reported in pregnant women in OMT. Furthermore, we show that maternal treatment with methadone leads to a significantly higher brain concentration in the fetus compared with the dam. This finding suggests that methadone treatment during pregnancy entails a larger burden for the fetus than for the mother. In contrast, exposure to buprenorphine resulted in a significantly lower concentration in the fetal brain than in the maternal brain. Buprenorphine also allowed more favorable birth outcomes compared with methadone. Taken together, our data on short-term effects indicate that OMT with buprenorphine may be a better choice than methadone during pregnancy; however, prenatal exposure to OMT may have long-lasting consequences not revealed the first weeks after birth.

\section{Acknowledgments}

We thank Synne Steinsland and Triske Woshyar Salih for assistance in the laboratory and Marianne Skov-Skov Bergh and Thomas Berg for their support regarding the opioid and corticosterone concentrations analyses.

\section{Authorship Contributions}

Participated in research design: Kongstorp, Bogen, Stiris, Andersen. Conducted experiments: Kongstorp, Andersen.

Performed data analysis: Kongstorp.

Wrote or contributed to the writing of the manuscript: Kongstorp, Bogen, Stiris, Andersen.

\section{References}

Andersen JM, Olaussen CF, Ripel A, and Mørland J (2011) Long-term methadone treatment impairs novelty preference in rats both when present and absent in brain tissue. Pharmacol Biochem Behav 98:412-416.

Bajic D, Commons KG, and Soriano SG (2013) Morphine-enhanced apoptosis in selective brain regions of neonatal rats. Int J Dev Neurosci 31:258-266.

Barr GA, Zmitrovich A, Hamowy AS, Liu PY, Wang S, and Hutchings DE (1998) Neonatal withdrawal following pre- and postnatal exposure to methadone in the rat. Pharmacol Biochem Behav 60:97-104.

Bartolome MB and Kuhn CM (1983) Endocrine effects of methadone in rats; acute effects in adults. Eur $J$ Pharmacol 95:231-238.

Bartu AE, Ilett KF, Hackett LP, Doherty DA, and Hamilton D (2012) Buprenorphine exposure in infants of opioid-dependent mothers at birth. Aust $N Z \mathrm{~J}$ Obstet Gynaecol 52:342-347.

Bier JB, Finger AS, Bier BA, Johnson TA, and Coyle MG (2015) Growth and developmental outcome of infants with in-utero exposure to methadone vs buprenorphine. J Perinatol 35:656-659.

Chen HH, Chiang YC, Yuan ZF, Kuo CC, Lai MD, Hung TW, Ho IK, and Chen ST (2015) Buprenorphine, methadone, and morphine treatment during pregnancy: behavioral effects on the offspring in rats. Neuropsychiatr Dis Treat 11:609-618.

Chiang YC, Hung TW, Lee CW, Yan JY, and Ho IK (2010) Enhancement of tolerance development to morphine in rats prenatally exposed to morphine, methadone, and buprenorphine. J Biomed Sci 17:46.

Chiang YC, Ye LC, Hsu KY, Liao CW, Hung TW, Lo WJ, Ho IK, and Tao PL (2015) Beneficial effects of co-treatment with dextromethorphan on prenatally methadone-exposed offspring. J Biomed Sci 22:19.

Cleary BJ, Eogan M, O'Connell MP, Fahey T, Gallagher PJ, Clarke T, White MJ, McDermott C, O'Sullivan A, Carmody D, et al. (2012) Methadone and perinatal outcomes: a prospective cohort study. Addiction 107:1482-1492.

Coles LD, Lee IJ, Hassan HE, and Eddington ND (2009) Distribution of saquinavir, methadone, and buprenorphine in maternal brain, placenta, and fetus during two different gestational stages of pregnancy in mice. J Pharm Sci 98:2832-2846.

Concheiro M, Jones HE, Johnson RE, Choo R, and Huestis MA (2011) Preliminary buprenorphine sublingual tablet pharmacokinetic data in plasma, oral fluid, and sweat during treatment of opioid-dependent pregnant women. Ther Drug Monit 33: 619-626.

Concheiro M, Jones HE, Johnson RE, Choo R, Shakleya DM, and Huestis MA (2010) Maternal buprenorphine dose, placenta buprenorphine, and metabolite concentrations and neonatal outcomes. Ther Drug Monit 32:206-215.

Daly FM, Hughes RN, and Woodward LJ (2012) Subsequent anxiety-related behavior in rats exposed to low-dose methadone during gestation, lactation or both periods consecutively. Pharmacol Biochem Behav 102:381-389.

de Cubas MM and Field T (1993) Children of methadone-dependent women: developmental outcomes. Am J Orthopsychiatry 63:266-276.

Doberczak TM, Kandall SR, and Friedmann P (1993) Relationship between maternal methadone dosage, maternal-neonatal methadone levels, and neonatal withdrawal. Obstet Gynecol 81:936-940.

Drewes AM, Jensen RD, Nielsen LM, Droney J, Christrup LL, Arendt-Nielsen L, Riley J, and Dahan A (2013) Differences between opioids: pharmacological, experimental, clinical and economical perspectives. $\mathrm{Br}$ J Clin Pharmacol 75:60-78.

Drozdick J III, Berghella V, Hill M, and Kaltenbach K (2002) Methadone trough levels in pregnancy. Am J Obstet Gynecol 187:1184-1188.

Fajemirokun-Odudeyi O, Sinha C, Tutty S, Pairaudeau P, Armstrong D, Phillips T, and Lindow SW (2006) Pregnancy outcome in women who use opiates. Eur J Obstet Gynecol Reprod Biol 126:170-175.

Farid WO, Dunlop SA, Tait RJ, and Hulse GK (2008) The effects of maternally administered methadone, buprenorphine and naltrexone on offspring: review of human and animal data. Curr Neuropharmacol 6:125-150.

Fischer G, Eder H, Jagsch R, Lennkh C, Habeler A, Aschauer HN, and Kasper S (1998) Maintenance therapy with synthetic opioids within a multidisciplinary program - a stabilizing necessity for pregnant opioid dependent women. Arch Women Ment Health 1:109-116.

Gabrielsson JL, Johansson P, Bondesson U, and Paalzow LK (1985) Analysis of methadone disposition in the pregnant rat by means of a physiological flow model. $J$ Pharmacokinet Biopharm 13:355-372.

Gordon AL, Lopatko OV, Somogyi AA, Foster DJ, and White JM (2010) (R)- and (S)methadone and buprenorphine concentration ratios in maternal and umbilical cord plasma following chronic maintenance dosing in pregnancy. Br J Clin Pharmacol 70:895-902.

Hamilton KL, Harris AC, and Gewirtz JC (2013) Affective and neuroendocrine effects of withdrawal from chronic, long-acting opiate administration. Brain Res 1538:73-82.

Hein PR, Schatorjé JS, and Frencken HJ (1988) The effect of chronic methadone treatment on intra-uterine growth of the cynomolgus monkey (Macaca fascicularis). Eur J Obstet Gynecol Reprod Biol 27:81-85.

Hofer MA, Shair HN, and Brunelli SA (2002) Ultrasonic vocalizations in rat and mouse pups, Curr Protoc Neurosci Chapter 8, p Unit 8.14.

Hung CJ, Wu CC, Chen WY, Chang CY, Kuan YH, Pan HC, Liao SL, and Chen CJ (2013) Depression-like effect of prenatal buprenorphine exposure in rats. PLoS One 8:e82262. 
Hutchings DE, Hamowy AS, Williams EM, and Zmitrovich AC (1996) Prenatal administration of buprenorphine in the rat: effects on the rest-activity cycle at 22 and 30 days of age. Pharmacol Biochem Behav 55:607-613.

Hutchings DE, Hunt HF, Towey JP, Rosen TS, and Gorinson HS (1976) Methadone during pregnancy in the rat: dose level effects on maternal and perinatal mortality and growth in the offspring. J Pharmacol Exp Ther 197:171-179.

Hutchings DE, Towey JP, Gorinson HS, and Hunt HF (1979) Methadone during pregnancy: assessment of behavioral effects in the rat offspring. J Pharmacol Exp Ther 208:106-112.

Hutchings DE, Zmitrovich A, Brake SC, Malowany D, Church S, and Nero TJ (1992 Prenatal administration of methadone using the osmotic minipump: effects on maternal and offspring toxicity, growth, and behavior in the rat. Neurotoxicol Teratol 14:65-71.

Jansson LM, Choo RE, Harrow C, Velez M, Schroeder JR, Lowe R, and Huestis MA (2007) Concentrations of methadone in breast milk and plasma in the immediate perinatal period. $J$ Hum Lact 23:184-190.

Johnson RE, Jones HE, Jasinski DR, Svikis DS, Haug NA, Jansson LM, Kissin WB, Alpan G, Lantz ME, Cone EJ, et al. (2001) Buprenorphine treatment of pregnant opioid--dependent women: maternal and neonatal outcomes. Drug Alcohol Depend 63:97-103.

Jones HE, Kaltenbach K, Heil SH, Stine SM, Coyle MG, Arria AM, O'Grady KE, Selby P, Martin PR, and Fischer G (2010) Neonatal abstinence syndrome after methadone or buprenorphine exposure. N Engl J Med 363:2320-2331.

Kim E, Clark AL, Kiss A, Hahn JW, Wesselschmidt R, Coscia CJ, and Belcheva MM (2006) Mu- and kappa-opioids induce the differentiation of embryonic stem cells to neural progenitors. J Biol Chem 281:33749-33760.

Konijnenberg C and Melinder A (2011) Prenatal exposure to methadone and buprenorphine: a review of the potential effects on cognitive development. Child Neuropsychol 17:495-519.

Kunko PM, Smith JA, Wallace MJ, Maher JR, Saady JJ, and Robinson SE (1996) Perinatal methadone exposure produces physical dependence and altered behavioral development in the rat. J Pharmacol Exp Ther 277:1344-1351.

Lemon LS, Naimi A, Caritis SN, Platt RW, Venkataramanan R, and Bodnar LM (2018) The role of preterm birth in the association between opioid maintenance therapy and neonatal abstinence syndrome. Paediatr Perinat Epidemiol 32: 213-222.

Mactier H, Shipton D, Dryden C, and Tappin DM (2014) Reduced fetal growth in methadone-maintained pregnancies is not fully explained by smoking or socio-economic deprivation. Addiction 109:482-488.

Meyer MC, Johnston AM, Crocker AM, and Heil SH (2015) Methadone and buprenorphine for opioid dependence during pregnancy: a retrospective cohort study J Addict Med 9:81-86.

Minozzi S, Amato L, Bellisario C, Ferri M, and Davoli M (2013) Maintenance agonist treatments for opiate-dependent pregnant women (Abstract). Cochrane Database Syst Rev (12):CD006318.

Monnelly VJ, Hamilton R, Chappell FM, Mactier H, and Boardman JP (2019) Childhood neurodevelopment after prescription of maintenance methadone for opioid dependency in pregnancy: a systematic review and meta-analysis. Dev Med Child Neurol 61:750-760.

Nanovskaya T, Deshmukh S, Brooks M, and Ahmed MS (2002) Transplacental transfer and metabolism of buprenorphine. J Pharmacol Exp Ther 300:26-33.

Nekhayeva IA, Nanovskaya TN, Deshmukh SV, Zharikova OL, Hankins GD, and Ahmed MS (2005) Bidirectional transfer of methadone across human placenta. Biochem Pharmacol 69:187-197.

Nørgaard M, Nielsson MS, and Heide-Jørgensen U (2015) Birth and neonatal outcomes following opioid use in pregnancy: a Danish population-based study. Subst Abuse 9 (Suppl 2):5-11.

Nygaard E, Moe V, Slinning K, and Walhovd KB (2015) Longitudinal cognitive development of children born to mothers with opioid and polysubstance use. Pediatr Res 78:330-335.

Nygaard E, Slinning K, Moe V, and Walhovd KB (2017) Cognitive function of youths born to mothers with opioid and poly-substance abuse problems during pregnancy. Child Neuropsychol 23:159-187.

Ohtani M, Kotaki H, Uchino K, Sawada Y, and Iga T (1994) Pharmacokinetic analysis of enterohepatic circulation of buprenorphine and its active metabolite, norbuprenorphine, in rats. Drug Metab Dispos 22:2-7.
Peters MA, Turnbow M, and Buchenauer D (1972) The distribution of methadone in the nonpregnant, pregnant and fetal rat after acute methadone treatment. $J$ Pharmacol Exp Ther 181:273-278.

Pontani RB, Vadlamani NL, and Misra AL (1985) Disposition in the rat of buprenorphine administered parenterally and as a subcutaneous implant. Xenobiotica 15:287-297.

Robinson SE, Guo HZ, McDowell KP, Pascua JR, and Enters EK (1991) Prenatal exposure to methadone affects central cholinergic neuronal activity in the weanling rat. Brain Res Dev Brain Res 64:183-188

Robinson SE and Wallace MJ (2001) Effect of perinatal buprenorphine exposure on development in the rat. $J$ Pharmacol Exp Ther 298:797-804.

Ross EJ, Graham DL, Money KM, and Stanwood GD (2015) Developmental consequences of fetal exposure to drugs: what we know and what we still must learn. Neuropsychopharmacology 40:61-87.

Sarfi M, Martinsen H, Bakstad B, Røislien J, and Waal H (2009) Patterns in sleepwakefulness in three-month old infants exposed to methadone or buprenorphine. Early Hum Dev 85:773-778.

Sargeant TJ, Miller JH, and Day DJ (2008) Opioidergic regulation of astroglial/ neuronal proliferation: where are we now? J Neurochem 107:883-897.

Sarman I (2000) Methadone treatment during pregnancy and its effect on the child: better than continuing drug abuse, should be monitored by a specialized antenatal care center. Lakartidningen 97:2182-2184, 2187-2188, 2190.

Saxon AJ, Hser YI, Woody G, and Ling W (2013) Medication-assisted treatment for opioid addiction: methadone and buprenorphine. Yao Wu Shi Pin Fen Xi 21: S69-S72.

Sundelin Wahlsten V and Sarman I (2013) Neurobehavioural development of preschool-age children born to addicted mothers given opiate maintenance treatment with buprenorphine during pregnancy. Acta Paediatr 102:544-549.

Van Wagoner S, Risser J, Moyer M, and Lasky D (1980) Effect of maternally administered methadone on discrimination learning of rat offspring. Percept Mot Skills 50: $1119-1124$

Volpe DA, McMahon Tobin GA, Mellon RD, Katki AG, Parker RJ, Colatsky T, Kropp TJ, and Verbois SL (2011) Uniform assessment and ranking of opioid $\mu$ receptor binding constants for selected opioid drugs. Regul Toxicol Pharmacol $\mathbf{5 9}$ 385-390.

Welle-Strand GK, Skurtveit S, Jones HE, Waal H, Bakstad B, Bjarkø L, and Ravndal E (2013) Neonatal outcomes following in utero exposure to methadone or buprenorphine: a National Cohort Study of opioid-agonist treatment of Pregnant Women in Norway from 1996 to 2009. Drug Alcohol Depend 127:200-206.

World Health Organization (WHO) (2014) Guidelines for the Identification and Management of Substance Use and Substance Use Disorders in Pregnancy pp 1-224, WHO, Geneva, Switzerland.

Wolburg H and Lippoldt A (2002) Tight junctions of the blood-brain barrier: development, composition and regulation. Vascul Pharmacol 38:323-337.

Wu VW, Mo Q, Yabe T, Schwartz JP, and Robinson SE (2001) Perinatal opioids reduce striatal nerve growth factor content in rat striatum. Eur J Pharmacol 414 211-214

Wurst KE, Zedler BK, Joyce AR, Sasinowski M, and Murrelle EL (2016) A Swedish population-based study of adverse birth outcomes among pregnant women treated with buprenorphine or methadone: preliminary findings. Subst Abuse 10:89-97.

Zagon IS and McLaughlin PJ (1977) The effects of different schedules of methadone treatment on rat brain development. Exp Neurol 56:538-552.

Zagon IS and McLaughlin PJ (1982) Analgesia in young and adult rats perinatally exposed to methadone. Neurobehav Toxicol Teratol 4:455-457.

Zagon IS, McLaughlin PJ, and Thompson CI (1979) Learning ability in adult female rats perinatally exposed to methadone. Pharmacol Biochem Behav 10: 889-894.

Zedler BK, Mann AL, Kim MM, Amick HR, Joyce AR, Murrelle EL, and Jones HE (2016) Buprenorphine compared with methadone to treat pregnant women with opioid use disorder: a systematic review and meta-analysis of safety in the mother, fetus and child. Addiction 111:2115-2128.

Address correspondence to: Mette Kongstorp, Oslo University Hospital, PO Box 4950 Nydalen, N-0424 Oslo, Norway. E-mail: mette.kongstorp@ous-hf.no 